\title{
Initial Experience with Open Heart Surgery in Sub-Saharan Africa: Challenges in Mali with Minimum Standards for Practice
}

\author{
${ }^{1}$ Department of Thoracic and Cardiovascular Surgery, Mali Hospital, Bamako, Mali \\ ${ }^{2}$ Department of Anesthesiology and Critical Care, Mali Hospital, Bamako, Mali \\ ${ }^{3}$ Department of Cardiologie, Mali Hospital, Bamako, Mali \\ ${ }^{4}$ Department of Pediatrics, Mali Hospital, Bamako, Mali \\ ${ }^{5}$ Department of Biomedical Laboratory, Mali Hospital, Bamako, Mali \\ ${ }^{6}$ Department of Surgery “A”, Point G Hospital, Bamako, Mali \\ Email: *drseydoutg@yahoo.fr
}

Seydou Togo ${ }^{*}$, Moussa Abdoulaye Ouattara1, Abdoul Aziz Maïga1, Moussa Bazongo1, Issa Boubacar Maïga1, Cheik Ahmed Sékou Touré2, Ibrahim Coulibaly1', Sounkalo Diop1, Allaye Ombotimbe1, Sitta Illiassou', Souleymane Coulibaly1, Mamadou Solo Koita1, Koumba Nelly Dora Ignanga ${ }^{1}$, Sanibé Dramane Koné1, Moussa Oscar Kamano', Fatoumata Konaté1, Adama Issa Koné1, Amadou Sidibé2, Ahmadou Dramé2, Nouhoum Oueloguem³, Bourama Kané4, Boubacar Dramé5, Sékou Koumaré6, Zimogo Zié Sanogo6, Sadio Yéna1

How to cite this paper: Togo, S., Ouattara, M.A., Maïga, A.A., Bazongo, M., Maïga, I.B., Touré, C.A.S., Coulibaly, I., Diop, S., Ombotimbe, A., Illiassou, S., Coulibaly, S., Koita, M.S., Ignanga, K.N.D., Koné, S.D., Kamano, M.O., Konaté, F., Koné, A.I., Sidibé, A., Dramé, A.I., Oueloguem, N., Kané, B., Dramé, B., Koumaré, S., Sanogo, Z.Z. and Yéna, S. (2019) Initial Experience with Open Heart Surgery in Sub-Saharan Africa: Challenges in Mali with Minimum Standards for Practice. World Journal of Cardiovascular Surgery, 9, 108-118.

https://doi.org/10.4236/wjcs.2019.99013

Received: July 23, 2019

Accepted: September 13, 2019

Published: September 16, 2019

\begin{abstract}
Introduction: There has been limited experience with Open Heart Surgeries (OHS) in Sub-Saharan Africa. In west Africa especially in Mali, most fledgling centers are unable to overcome the myriad of challenges encountered in establishing OHS though there is a high prevalence of surgically correctable heart diseases. The aim of this paper is to review our initial experience of our first cases in developing OHS program and discuss the challenges and prospects that need to be overcome to further develop it. Methods: A total of 6 patients who underwent OHS during the first "cardiac mission" in July 2016 were included in this retrospective study. The medical records of the patients were examined and data on age, sex, diagnosis, EuroSCORE, type of surgery, cardiopulmonary bypass details, complications and length of hospital stay were extracted. Results: Six patients with a male to female ratio of 1 , ages ranging between 12 and 35 years (mean of $22.5 \pm 12$ years) were studied. The mean of EuroSCORE was $6 \pm 41$. Pericardial patch closure of isolated atrial septal defect was performed in one patient. One patient had mitral valve repair for rheumatic mitral regurgitation consisting of chordal shortening with
\end{abstract}


Copyright $\odot 2019$ by author(s) and Scientific Research Publishing Inc. This work is licensed under the Creative Commons Attribution International License (CC BY 4.0).

http://creativecommons.org/licenses/by/4.0/

Open Access a tricuspid valvuloplasty. Three patients had mitral valve replacement with tricuspid valvuloplasty. Four patients had mitral valve replacement. Sixty-day mortality was $0 \%$. Conclusion: Safe conduct of open heart surgery in Mali Hospital setting is feasible. Grant financial aid is required for rapid growth of Open-Heart Surgery in this part of Sub-Saharan Africa.

\section{Keywords}

Open-Heart, Surgery, Mali, Africa

\section{Introduction}

Open Heart Surgery (OHS) is defined as "surgical repair of the heart during which the blood circulation is often maintained mechanically requiring Cardiopulmonary Bypass (CPB)" [1]. There has been limited experience with OHS in West Africa with only a few established cardiac centers [2] [3]. In Mali most fledgling centers are unable to overcome the myriad of challenges encountered in establishing OHS though there is a high prevalence of surgically correctable heart diseases. OHS is relatively expensive as income is low in Mali. It has been demonstrated that in sub-Saharan Africa, gross domestic product (GDP) per capita remains low comparing to OHS cost, which remains beyond the reach of our population's financial capacities [4]. Confronted with this deficit, funding from our States is insignificant or does not exist at all in some of them [5]. Cardiothoracic practice in Mali faces multiple challenges that need to be overcome to enable sustainable practice. A seed fund was provided by the Malian government which was used as the start of specialized cardiac training abroad. A small fraction of patients are sponsored or are able to fund their own surgery abroad but the goal for any country has to be to establish its own programs that can be developed and sustained. Despite some early attempts to develop OHS in Mali [6], this has not been sustained. An OHS program is in the first time being performed at the Mali University Teaching Hospital. It is encouraging to see the surge in OHS activity but we need to transit from cardiac missions. Successful OHS requires 24-hour laboratory support, an active blood bank and cardiac catheterization support. Access to these various support facilities were very limited in sub-Saharan Africa. The aim of this article is to share the result of our first cases in developing OHS program and discuss the challenges and prospects that need to be overcome to further develop and sustain it.

\section{Patients and Methods}

Surgical treatment for heart diseases did not exist in Mali located in sub-Saharan Africa and early death was inevitable. For several years the Mali government has sponsored few needy patients to undergo OHS abroad. Since 2009 a makeshift cardiac centre was under construction in Mali without a serious sustain program 
by the government to develop it. In spite of our challenges, our human and economic potential enable us to anticipate positive developments, including rapid growth of OHS. To overcome these challenges a "Cardiac Mission" was then organized with patients recruited and screened by the local cardiologists of our hospital. The core of the local Cardiac Team is made up of 2 cardiac surgeons, 2 cardiologists, 1 Cardiac anaesthetist, 1 intensivist, and 6 theatre nurses. This team works with the Morocco "Cardiac Mission" team which contributes a further 3 cardiac surgeons 2 theatre nurses, 4 intensive care nurses and 1 perfusionist. During the cardiac mission, OHS consumables are sourced from Morocco team and all procedures were entirely free for the selected patients. The surgery was performed by the Morocco team as an international humanitarian service for OHS which also provided all the equipment and materials required for OHS. The first 6 OHS cases were performed in 2016 with success in Mali University Teaching Hospital. Clinical assessment and appropriate investigations are done. Transthoracic echocardiography was performed in all cases for diagnosis. For the inclusion criteria, the euroscore is computed and if deemed acceptable the patient is offered surgery. High risk patients are discussed with Cardiac surgeons, cardiologists and anesthesists before surgery. The exclusion critera for this study was the patients who had an indication of open-heart surgery and could not be operated for technical reasons (suspicion of coronary artery disease without possibility for coronarography or coronary angiography); patients that conditions were associated with active viral hepatitis, positive for HIV, morbid obesity and global heart failure; patients selected for surgery are put on a waiting list. Mitral valve disease was of rheumatic origin in five cases (4 cases of mitral valve stenosis and 1 case of mitral regurgitation), and there was one case of congenital heart disease (atrial septal defect). The surgery is performed by the Morocco team and assisted by the local team. Cardiac surgery missions do have adult heart surgery arm and only an infrequent congenital programme. Patients are admitted 7 days before surgery and a checklist is used to assess that there are no impediments to the surgery. Following aortic and bicaval cannulation, cardiopulmonary bypass was instituted with the heart lung machine. All cases have been done with the Stockert Compact heart lung machine (Sorin, Italy). All patients underwent surgery utilizing aortic, bicaval cannulation. Myocardial protection was with blood cardioplegia in all cases with retrograde approach and moderate systemic hypothermia $\left(30^{\circ} \mathrm{C}-32^{\circ} \mathrm{C}\right)$. Following surgery the patients were transferred to the Intensive Care unit and once weaned off cardiac or respiratory support, the patients were moved to a side room of cardiothoracic surgery department. The patients were usually seen 2 weeks afterwards in the cardiothoracic department, and further follow up was done with the cardiologysts of the hospital. The medical records of the patients were examined and data on age, sex, diagnosis, type of surgery, cardiopulmonary bypass details, complications and length of hospital stay were extracted. After been discharged from the hospital, patients were followed up weekly at the first and second month to seek ur- 
gent care for any potentially serious symptoms. Recovery at home after leaving the hospital usually takes between 4 to 6 weeks. The healthcare team guide rehabilitation and advice on medications and restrictions on physical activity. Then patients has regular checkup one's a month for about 1 year. In echographic follow-up comparison is made to show the relation between preoperative left ventricular diameter and the possibility of postoperative ventricular recuperation after mitral valve replacement. Patients consent was obtained before this study and permission was obtained from the Ethics Committee of the Mali University Teaching Hospital for use of the patient data from the database. The results are presented below, as well as the challenges encountered in achieving these results. Data are expressed as absolute values, percentages, or mean \pm SD where appropriate. Fisher exact test was used for statistical analysis and $\mathrm{P}<0.05$ was statistically significant.

\section{Results}

A total of 6 OHS cases were performed during 7 days in our hospital. The patients had a mean age of $22.5 \pm 12$ years (range: 12 - 33 years) with a male to female ratio of 1 . The patients in all had a mean weight of $25.8 \pm 10.9$ and a body surface area of $0.56 \pm 0.5 \mathrm{~m}^{2}$. Three patients had mild clinical cardiac decompensation (50.0\%) in New York Heart Association (NYHA) class 2 while they were no NYHA class 3 and NYHA class 4 in the patients selected. The various anatomical lesions in echocardiography were dilatation of the mitral ring, dilatation of the heart chambers, thrombi in the atria, atrial septal defect, and valve calcification, leakage and stenosis. Sociodemographic and clinical characteristics were found in Table 1. Pericardial patch closure of isolated atrial septal defect was done in 1 patient. One patient with rheumatic mitral regurgitation aged 12 years had mitral valve repair for rheumatic mitral regurgitation consisting of chordal shortening with tricuspid valvuloplasty using the De Vega method. Four patients had mitral valve replacement with tricuspid valvuloplasty by the De Vega method. Surgical removal of the thrombi and closure of the left atrial appendage were performed after mitral valve replacement in 2 patients. Table 2 shows age, euroscore the various pathologies encountered and types of OHS procedures performed.

The mean cardiopulmonary bypass time was $94.67 \pm 41.95$ minutes (Range $=$ 62 - 170 minutes) and the aortic cross-clamp time was $68.83 \pm 33.35$ minutes (Range $=34-110$ minutes). The cardiopulmonary bypass time for patients with valve replacement was $127.7 \pm 48.3$ minutes. Postoperative mechanical ventilation was for $15.83 \pm 4.91$ minutes while the post-operative intensive care unit stay was $46.9 \pm 36.5$ hours. Blood transfusion was done in 2 patients. The complications seen in this case series were ventricular fibrillation with inotropic/pacemacker support in 1 patient, atrial fibrillation/supraventricular tachycardia in 1 patients $(11.8 \%)$, Fever requiring antibiotic treatment in 1 patients $(13.7 \%)$, pericardial effusion requiring drainage in 1 patients $(11.8 \%)$, superficial sternal wound 
Table 1. Sociodemographic and clinical characteristics.

\begin{tabular}{|c|c|c|}
\hline Patients characteristics & Frequency & $\%$ \\
\hline \multicolumn{3}{|l|}{ Sex } \\
\hline Male & 3 & 50 \\
\hline Female & 3 & 50 \\
\hline \multicolumn{3}{|l|}{ Age (years) } \\
\hline $5-20$ & 2 & 33.3 \\
\hline$>20$ & 4 & 66.7 \\
\hline Mean age: & \multicolumn{2}{|c|}{$22.5 \pm 12$ (range: $12-33)$} \\
\hline \multicolumn{3}{|l|}{ Weight (Kg) } \\
\hline $10-30$ & 2 & 33.3 \\
\hline$>30$ & 4 & 66.7 \\
\hline Mean weight: & \multicolumn{2}{|c|}{$25.8 \pm 10.9($ range: $15-62)$} \\
\hline \multicolumn{3}{|l|}{ Body surface area $\left(\mathrm{m}^{2}\right)$} \\
\hline $0.5-1.0 \mathrm{~m}^{2}$ & 4 & 66.7 \\
\hline $1.0-1.5 \mathrm{~m}^{2}$ & 2 & 33.3 \\
\hline Mean body surface area: & \multicolumn{2}{|c|}{$0.56 \pm 0.5 \mathrm{~m}^{2}$} \\
\hline \multicolumn{3}{|l|}{ New York Heart Association class } \\
\hline 2 & 6 & 100 \\
\hline \multicolumn{3}{|l|}{ Diagnosis } \\
\hline \multicolumn{3}{|l|}{ - Congenital heart disease: } \\
\hline ASD $($ secundum $=2.5 \mathrm{~mm})$ & 1 & 16.7 \\
\hline \multicolumn{3}{|l|}{ - Acquired heart disease: } \\
\hline Severe rheumatic mitral stenosis & 1 & 16.7 \\
\hline Severe rheumatic mitral regurgitation + tricuspid insufficiency & 4 & 66.6 \\
\hline
\end{tabular}

ASD: Atrial Septal Defect.

Table 2. Shows age, EuroSCORE, the various pathologies encountered and types of OHS procedures performed.

\begin{tabular}{|c|c|c|c|c|c|}
\hline $\begin{array}{l}\text { Patient } \\
\text { number }\end{array}$ & Age & EuroSCORE & Diagnosis & Pathology & Surgical procedure \\
\hline 1 & 24 & 3 & Atrial septal defect & Secundum $(25 \mathrm{~mm})$ & Autologous pericardium closure \\
\hline 2 & 12 & 6 & MV disease & $\begin{array}{l}\text { MV regurgitation } \\
+ \text { TV regurgitation }\end{array}$ & $\begin{array}{l}\text { Mitral valve repair + tricuspid valvuloplasty by } \\
\text { "De Vega" Method }\end{array}$ \\
\hline 3 & 23 & 4 & Mitral valve disease & MV stenosis + TV regurgitation & $\begin{array}{l}\text { Mechanical Mitral valvereplacement }+ \text { Tricuspid } \\
\text { Valvuloplasty by "De Vega" Method }\end{array}$ \\
\hline 4 & 15 & 10 & Mitral valve disease & $\begin{array}{l}\text { MV stenosis + TV regurgitation } \\
+ \text { thrombi in left atrium }\end{array}$ & $\begin{array}{l}\text { Mechanical Mitral valve replacement }+ \text { Tricuspid } \\
\text { Valvuloplasty by "De Vega" Method + thrombi } \\
\text { removal and left atrial appendage closure }\end{array}$ \\
\hline 5 & 29 & 5 & Mitral valve disease & MV stenosis & Mechanical Mitral valve replacement \\
\hline 6 & 35 & 8 & Mitral valve disease & $\begin{array}{l}\text { MV stenosis + TV regurgitation } \\
+ \text { thrombi in left atrium }\end{array}$ & $\begin{array}{l}\text { Mechanical Mitral valve replacement + Tricuspid } \\
\text { Valvuloplasty by "De Vega" Method + thrombi } \\
\text { removal and closure of the left atrial appendage }\end{array}$ \\
\hline
\end{tabular}

EuroSCORE: European System for Cardiac Operative Risk Evaluation, MV: Mitral Valve, TV: Tricuspid Valve. 
infection in 1 patients (7.8\%). Table 3 is a summary of the procedures which includes the distribution of cardiopulmonary bypass time, cross clamp time and postoperative complications. The post-operative hospital stay was $9.1 \pm 2.4$ days and the overall mortality in the series was null. The patients were symptom-free at the 6-month follow-up clinic visit and trans-thoracic echocardiography done then did not show any deterioration in the degree of mitral valve or tricuspid valve regurgitation. All of the patients (100\%) were in NYHA class I. Long term (4 years) follow-up is being done on these patients. The comparative echographic result before and after surgery are presented in Table 4.

\section{Discusions}

Since 1950s, one of the major challenges was to accomplish correction of intracardiac lesions within a bloodless heart using a heart-lung machine. Throughout

Table 3. Operative details, complications and mortality.

\begin{tabular}{ccccccc}
\hline $\begin{array}{c}\text { Patient } \\
\text { number }\end{array}$ & Age & Operations & $\begin{array}{c}\text { CPB } \\
(\mathrm{min})\end{array}$ & $\begin{array}{c}\text { X Clamp } \\
(\mathrm{min})\end{array}$ & Complications & Mortality \\
\hline $\mathbf{1}$ & 24 & ASD & 92 & 73 & $\begin{array}{c}\text { Superficial wound } \\
\text { infection }\end{array}$ & 0 \\
$\mathbf{2}$ & 12 & MV repair + TV & 146 & 96 & - & 0 \\
$\mathbf{3}$ & 23 & MVR + TV + LAC & 149 & 101 & Fever & 0 \\
$\mathbf{5}$ & 15 & MVR + TV & 132 & 95 & Pericardial effusion & 0 \\
6 & 29 & MVR & 136 & 98 & $\begin{array}{c}\text { Atrial fibrillation } \\
\text { (tachycardia) }\end{array}$ & 0 \\
\hline
\end{tabular}

ASD: Atrial Septal Defect. MV: Mitral Valve. TV: Tricuspid Valvuloplasty. CBP: Cardio-Pulmonary Bypass time. MVR: Mitral Valve Replacement. X Clamp: Aortic cross Clamp Time. LAC: Left Atrial Closure.

Table 4. Comparison of Ejection fraction, left ventricular end-systolic diameter, left ventricular end-diastolic diameter in patients with mitral valve replacement.

\begin{tabular}{|c|c|c|c|c|}
\hline Variables & $\begin{array}{c}\text { Preoperative } \\
\text { (G1) }\end{array}$ & $\begin{array}{c}\text { Early } \\
\text { postoperative (G2) }\end{array}$ & $\begin{array}{c}\text { Late } \\
\text { postoperative (G3) }\end{array}$ & $P$ value \\
\hline \multirow{3}{*}{$\mathrm{FE}$} & \multirow{3}{*}{$42 \pm 8$} & \multirow{3}{*}{$47.8 \pm 10$} & \multirow{3}{*}{$60.3 \pm 10$} & G3 Vs G1 $\mathrm{p}<0.001^{*}$ \\
\hline & & & & G3 Vs G2 p $<0.001^{\star}$ \\
\hline & & & & G2 Vs G1 $\mathrm{p}<0.001^{*}$ \\
\hline \multirow{3}{*}{ LVED } & \multirow{3}{*}{$61 \pm 7.4$} & \multirow{3}{*}{$59.3 \pm 8$} & \multirow{3}{*}{$51.2 \pm 8$} & G3 Vs G1 $p<0.001^{*}$ \\
\hline & & & & G3 Vs G2 $p<0.001^{*}$ \\
\hline & & & & G2 Vs G1 $\mathrm{p}<0.001^{\star}$ \\
\hline \multirow{3}{*}{ LVES } & \multirow{3}{*}{$48 \pm 8$} & \multirow{3}{*}{$45.4 \pm 8.4$} & \multirow{3}{*}{$40 \pm 7.5$} & G3 Vs G1 p $<0.001^{*}$ \\
\hline & & & & G3 Vs G2 p $<0.001^{*}$ \\
\hline & & & & G2 Vs G1 p $<0.001^{*}$ \\
\hline
\end{tabular}

${ }^{*}$ Significant for $\mathrm{p}<0.05$. LVES: Left Ventricular End-Systolic Diameter; EF: Ejection Fraction; LVED: Left Ventricular End-Diastolic Diameter. 
the history of surgery in the world, challenges were constantly part of the way forward, and this is certainly true for open heart surgery (OHS). In the past, challenges often inspired surgeons to develop innovative treatments leading to better quality of OHS performance. Therefore, challenges had a positive impact on the development of OHS over the last century. The problem of cardiovascular disease in Mali and sub-Saharan Africa is considerable and will be more and more so if nothing is done. The rate of the Malian population with heart disease was estimated at $15 \%$, or about $1,600,000$ patients [7]. Among them $8 \%$ of the Malian population with heart disease need OHS. The difficulties for the vast majority of patients to provide surgical treatment both locally and abroad considerably reduce their life expectancy. A large majority of the population is economically poor and poor. Indeed in Mali, the average cost of medical evacuation was evaluated per patient at 16,300 euros [8]. The results described above have been achieved against a background of a number of challenges. The haematology department has been very supportive but has a number of constraints. Blood products can be obtained (fresh frozen plasma, platelets, cryoprecipitate) but require a lot of advance notice for preparation. Relations and friends of intending patients are therefore encouraged to donate. Routine preparation for each OHS case that will require CPB is 4 units of packed cells, 4 units of platelets, 4 units of Fresh Frozen Plasma. Radiology has been particularly challenging. In the cardiac mission transthoracic echocardiography was available using a ultrasound machine (sonosite) which lacked adequate resolution and contributed to some cases being inadequately diagnosed. The OHS in our institution has involved the surgery being done in a regular operating theater. This is a part of challenges which are not unusual in a developing country. Funding is irregular which has caused difficulty in getting equipment and stock of consumables. Electrical power is a major issue and the power surges which often occur risk damage to vital equipment. The hospital is also powered by 2 generators. As these are in constant use they often break down and it is therefore part of the checklist to liaise with the engineering department to be sure power is guaranteed during the period of surgery. Efforts have been made to get foreign teams to visit more frequently but unfortunately financial considerations have so far limited this option. Mitral valve repair in patients with favorable mitral valve apparatus is recommended [9] as it precludes the adverse complications associated with prosthetic mechanical valves and anticoagulation including prosthetic valve thrombosis and embryotoxicity of warfarin [9] [10]. For those reasons, one young age patient (12 years) received mitral valve repair during the OHS mission. Postoperatively, the patients were transferred to the intensive care unit and most had early extubation and weaning from mechanical ventilation after adequate recovery from anaesthesia using a fasttracking approach which is recommended even in the paediatric population by various authors [11] [12]. This approach resulted in over $75 \%$ of our patients being discharged from the hospital within 7 days of surgery African surgeons faced several and multifaceted chal- 
lenges in practicing OHS in our region: sub-Saharan Africa [13] [14]. As far as open-heart surgery is concerned, socio-economic barriers are one of the major challenges; they are in proportion to a rapid poverty growth, sometimes political instability, bad governance, widespread corruption and a lack of universal health coverage. Looking at the unfavorable factors of growth index in sub-Saharan African countries, it may be considered impossible for our states to provide consistent and/or complete financing for the daily running of open-heart surgery centers in terms of maintenance of existent infrastructures and equipment and providing the necessary supplies. The challenges are also political; armed conflicts and ongoing rebellions provide a fertile ground for political instability that is sometimes chronic in some countries; this often prevents financial investment, which on the one hand increases the problems related to the lack of medical infrastructures for growing populations, and on the other hand, explains the lack of more efficient supply chain for medical equipment. It is also a pity to notice that open-heart surgery is not a priority for our governments. The great financial efforts are mainly brought to the fight against infectious and parasitic diseases: Diarrhea, Malnutrition, Malaria, and AIDS/HIV. Nowadays, in Africa, according to WHO [15], rheumatic heart diseases attack more than 4 million people; they cause about 90,000 deaths per year. In addition, during the 20 or 40 next years, developing countries will be confronted with the persistence of both rheumatic cardiac diseases and atherosclerotic cardiovascular diseases. The insufficient infrastructure adds to the list of obstacles to open-heart surgery. Compared with the United States of America where there is one open-heart surgery center for 150,000 inhabitants or Europe with one for 1 million inhabitants, Africa has one center for 50 million people [16]. The weakness of our human resources is also one of the challenges of open-heart surgery in sub-Saharan Africa. There is a shortage of skilled health staff: the number of nurses, doctors or heart specialists is inferior to the actual needs. The consequence is a lack of diagnosis or a numerical undervaluation of cardiovascular diseases or a long diagnostic delay, so that in Cote d'Ivoire for example, $80 \%$ of the valvulopathies are diagnosed in the hospital at advanced stages of cardiac failure. Only few West-African centers have a regular open-heart surgery activity. The initial management of patients following cardiac surgery focuses on ensuring adequate analgesia, ventilation and managing bleeding and hypothermia. Maintaining cardiac output is important because it affects mean arterial pressure and tissue perfusion. Reduced tissue perfusion can lead to organ failure. Low cardiac output following cardiac surgery was managed by giving intravenous fluid therapy to increase and optimize preload, which increases the volume of each stroke and hence output. Inotropes, given by a central venous catheter, started when fluid therapy fails to provide an adequate effect. Mechanical ventilation was reduced and ended within 24 hours following surgery in our patients. Patients are given a course of antibiotics as prophylaxis for the first 24 hours after surgery. Patients who have had a mechanical valve implanted required lifelong anticoagulation to 
prevent valve thrombosis. Heparin was started shortly after surgery and "bridged" with an oral anticoagulant, usually warfarin. The target INR is dependent on patient risk factors, thrombogenicity of the prosthesis used [17] and the position of the valve that was replaced. Mitral valve replacement poses greater risk of thrombosis. Atrial fibrillation is common after cardiac surgery, and typically occurs two to four days after the operation [18]. The incidence is around $40 \%$ after valve surgery [18]. Most patients will convert spontaneously back to sinus rhythm in 24 hours [18]. Beta blockers are used to reduce the risk of atrial fibrillation. The European Society of Cardiology (ESC) guidelines recommend ventricular rate control for patients who develop AF following surgery, or direct current cardioversion for patients with AF and haemodynamic instability [18]. Anticoagulants are started if AF persists for more than 48 hours [18]. Epicardial pacing wires placed in-situ, help to detect and treat post-operative arrhythmias. The choice of whether to use a pacing wire depends on the surgeon and it has been used in one patient. Infection of the sternal wound occurs in up to $5 \%$ of patients [19]. It is normally detected within two weeks of surgery, although it can occur more than a month later. Treatment includes surgical debridement, sternal rewiring, intravenous antibiotics, and vacuum assisted closure (VAC) therapy which uses negative pressure to promote wound healing. One patient with superficial sternal wound was treated by intravenous antibiotics only. Fortunately, despite challenges enumerated [20] [21], and serious difficulties met, as said, a few cardiac centers in sub-Africa continue to offer OHS. However, the progress of medicine including heart surgery must have respect for the fundamental ethics for the benefit of humanity and Human Rights. The success of this mission was achieved with minors' complications and the mortality was null. We found an improvement in the functional class of NYHA after surgery (100\% of our patients were in NYHA class I). This functional improvement was well correlated with the degree of recovery of left ventricular function. It has been reported that there is a close relationship between LV size preoperatively and the possibility of ventricular recovery. Thus, author reported that patients with preoperative LV DTD $\leq 55 \mathrm{~mm}$ were more likely to improve their left ventricular function [22].

Morris and al reported that patients who had an improvement in the postoperative ejection fraction had a better survival curve [23]. The mission of that cooperation would be to help reinforce skills in terms of professional competences, exchanges, knowledge, innovative surgical techniques, new technologies, equipment and human resources. Reinforce scientific exchanges among cardio-vascular surgeons in Africa through growing programs of open-heart surgery which need to be sustained. Urgent assistance in seeking funding for patients is therefore required and the options available include the government, non-governmental organizations, foundations and establishment of national health insurance schemes. With the satisfaction of the patients and their families following this mission of open heart surgery, the local team bases their hopes on the sustainability of this south-south cooperation, while waiting for the training 
and the empowerment of the Malian teams for the relay. This autonomy will, in the near future, give the Malian population access to cardiac surgery at a lower cost. Regarding to this operating result in our hospital, further cardiac missions were starting organized in others hospitals to performed OHS in Mali.

\section{Conclusion}

By encouraging international humanitarian services for OHS in developing countries without any capacity to take care of patients with acquired or congenital heart disease, OHS can be done with success in Mali. Grant financial aid to the care of the poorest patients by public, governmental or private initiatives is required for rapid growth of Open-Heart Surgery in sub-Saharan Africa.

\section{Conflicts of Interest}

The authors declare no conflicts of interest regarding the publication of this paper.

\section{References}

[1] Open-Heart Surgery (2012) Collins English Dictionary-Complete \& Unabridged. 10th Edition. Dictionary.com. http://dictionary.reference.com/browse/open-heartsurgery

[2] Anyanwu, C.H., Ihenacho, H.N., Okoroma, E.O., et al. (1982) Initial Experience with Open Heart Surgery in Nigeria. Tropical Cardiology, 8, 123-127.

[3] Adebonojo, S.A., Grillo, I.A. and Osinowo, O. (1981) Initial Experience with Open Heart Surgery at University College Hospital, Ibadan, Nigeria. Tropical Cardiology, 7, 49-54.

[4] Adebonojo, S.A. (2012) How Viable Are the Cardiac Programmes in West Africa Today? In: Adebonojo, S.A., Ed., Development of Open Heart Surgery in West Africa: A Historical Perspective, Acecool Medical Publishers: Nigeria, Eruwa, 43-46.

[5] Diakité, A., Sidibé, N. and Diarra, M.B. (2009) Epidemiological and Clinical Aspects of Congenital Heart Disease. Mali Médical, 24, 67-68.

[6] Coulibaly, B., Diarra, M. and Dicko, M. (2014) Angers-Bamako Cooperation in the Context of Cardiovascular Surgery: Situation and Perspectives: Is Open Heart Surgery Feasible in Mali? Journal de la SFCTCV, 18, 55-58.

[7] Yangni-Angate, K.H. (2016) Open heart surgery in Sub-Saharan Africa: Challenges and Promise. Cardiovascular Diagnosis and Therapy, 6, S1-S4. https://doi.org/10.21037/cdt.2016.10.05

[8] Jean-François, M. (2007) Man Seeking Humanity. Presses Rebirth, Paris.

[9] Mvondo, C.M., Pugliese, M., Giamberti, A., Chelo, D., Kuate, L.M., Boombhi, J. and Dailor, E.M. (2016) Surgery for Rheumatic Mitral Valve Disease in Sub-Saharan African Countries: Why Valve Repair Is Still the Best Surgical Option. Pan African Medical Journal, 24, 307. https://doi.org/10.11604/pamj.2016.24.307.7504

[10] Masuda, M., Kado, H., Tatewaki, H., Shiokawa, Y. and Yasui, H. (2004) Late Results after Mitral Valve Replacement with Bileaflet Mechanical Prostheses in Children: Evaluation of Prosthesis-Patient Mismatch. The Annals of Thoracic Surgery, 77, 913-917. https://doi.org/10.1016/j.athoracsur.2003.09.066

[11] Cheng, D.C. (1998) Fast Track Cardiac Surgery Pathways: Early Extubation Process 
of Care and Cost Containment. Anaesthesiology, 88, 1429-1433. https://doi.org/10.1097/00000542-199806000-00002

[12] Neirotti, R.A., Jones, D., Hackbarth, R. and Paxson Fosse, G. (2002) Early Extubation in Congenital Heart Surgery. Heart, Lung and Circulation, 11, 157-161. https://doi.org/10.1046/j.1444-2892.2002.00144.x

[13] Falase, B., Sanusi, M., Majekodunmi, A., et al. (2013) Open Heart Surgery in Nigeria: A Work in Progress. Journal of Cardiothoracic Surgery, 8, 6. https://doi.org/10.1186/1749-8090-8-6

[14] Chelo, D., Nguefack, F., Ndombo, P.O., et al. (2016) Challenges of Surgical Management of Childhood Cardiac Diseases in Sub-Saharan Africa, Experience of a Pediatric Cardiology Unit in Yaounde, Cameroon. Pediatric Research, 1, 103.

[15] Howson, C.P., Reddy, K.S., Ryan, T.J., et al. (1998) Control of Cardiovascular Diseases in Developing Countries Research, Development, and Institutional Strengthening for Control of Cardiovascular Diseases in Developing Countries. National Academy Press, Washington DC. https://www.nap.edu/read/6218/chapter/1

[16] Pezzella, T.A. (2005) Global Expansion of Cardiothoracic Surgery. The African Challenge. African Annals of Thoracic and Cardiovascular Surgery, 1, 9-11.

[17] Vahanian, A., Alfieri, O., Andreotti, F., et al. (2012) Guidelines on the Management of Valvular Heart Disease (Version 2012). European Heart Journal, 33, 2451-2496. https://doi.org/10.1093/eurheartj/ehs109

[18] Camm, J.A., Kirchhof, P., Lip, G.Y.H., et al. (2010) Guidelines for the Management of Atrial Fibrillation. ESC Guidelines. European Heart Journal, 31, 2369-2429.

[19] Diez, C., Koch, D., Kuss, O., et al. (2007) Risk Factors for Mediastinitis after Cardiac Surgery-A Retrospective Analysis of 1700 Patients. Journal of Cardiothoracic Surgery, 2, 23. https://doi.org/10.1186/1749-8090-2-23

[20] Nigeria Country Data Profile. World Bank. http://web.worldbank.org

[21] Adebonojo, S.A., Grillo, I.A., Osinowo, O., Adebo, O.A., Akinyemi, O., Famewo, C.E., Idowu, A.L. and Osanyintuyi, S.O. (1981) Initial Experience with Open Heart Surgery at University College Hospital, Ibadan, Nigeria. Tropical Cardiology, 7, 49-54.

[22] Une, D., Mesana, L., Chan, V., Maklin, M., Chan, R., Masters, R.G., et al. (2015) Clinical Impact of Changes in Left Ventricular Function after Aortic Valve Replacement. Circulation, 132, 741-747. https://doi.org/10.1161/CIRCULATIONAHA.115.015371

[23] Morris, J.J., Schaff, H.V., Mullany, C.J., Rastogi, A., McGregor, C.G., Daly, R.C., et al. (1993) Determinants of Survival and Recovery of Left Ventricular Function after Valve Replacement. The Annals of Thoracic Surgery, 56, 22-30. https://doi.org/10.1016/0003-4975(93)90398-2 